\title{
Anthropocentrism and sustainable development: oxymoron or symbiosis?
}

\author{
C. Speed \\ RMIT University, Australia
}

\begin{abstract}
This research focuses on the definition and achievement of sustainable development, and the factors that influence this. The aim is to understand the current situation in Western society, how and why we reached this point, and to determine a path forward that is genuinely sustainable. Within this context, this research paper will critically analyse the concept of anthropocentrism and the subsequent dominant cultural values, with particular emphasis on how they have framed our relationship with the built and natural environment. This will provide the framework to explore how this relationship, and the institutionalisation of anthropocentrism, has influenced the definition and achievement of sustainable development.

Keywords: anthropocentrism, sustainable development, nature, Christianity, scientific revolution, classical economics, progress.
\end{abstract}

\section{Introduction}

The ideological basis of Western society has been pivotal in shaping our perception of nature, thereby framing our relationship with the natural environment, and consequently legitimising our treatment of it. As such, this paper will provide an overview of the most significant factors shaping Western European society since antiquity. For the purposes of this research, Western European history has been divided into two ideological periods of time.

The first extends from the time of Christ until the scientific revolution in the sixteenth century. The dominant social authorities during this time were Christianity and science, the relative power of either generally inversely proportional to the other (with the exception of the thirteenth to the sixteenth centuries, during which time St Thomas Aquinas wrote Summa Theologiae which reconciled Christianity with Aristotle's cosmology). The dominant 
perception of nature during this period was that of a resource, created by God, over which man was bequeathed dominion.

The decline in the authority of the Church during the scientific revolution was concurrent with the elimination of spirituality from science, with severe consequences for the perception of nature. Since the scientific revolution, the dominant perception of nature has been in reductionist terms as that of a machine, which classical economics defined as capital for the sole purpose of extraction and production for the use of man.

Anthropocentrism was the common theme in Western European society during both periods, and remains as such in Western society today. Key questions to be explored within the presentation of this research include: (i) How has the current inherently human-centred paradigm (anthropocentrism) contributed to the definition of sustainable development? (ii) Is it possible to achieve true sustainable development within the current paradigm? Is it possible to re-define sustainable development within the current paradigm so that it is sustainable for all living systems, not just humans? (iii) Or do we need a radical re-thinking of anthropocentrism as a core element of Western society, and thus how we relate to and interact with the built and natural environment, in order to provide the framework to re-define sustainable development?

\section{The origins of anthropocentrism in Western society}

\subsection{Anthropocentrism in the Garden of Eden}

The origins of anthropocentrism and current Western thought regarding nature can be traced back to the elements of Christianity that it inherited from its Jewish origins $[1, \mathrm{p} .141]$. The view that humans were placed in a position of dominance over subordinate nature is derived from the two creation myths in Genesis in the Old Testament, originally a Jewish religious book.

In the first myth God created man in his own image on the sixth day, and God said "Be fruitful, and multiply, and replenish the earth, and subdue it: and have dominion over the fish of the sea, and over the fowl of the air, and over every living thing that moveth upon the earth" [2, Genesis 1:28]. The second creation myth outlines how man was created, followed by the Garden of Eden filled with plants and animals for the benefit of humanity, and finally women. In both these myths nature was created for purely utilitarian purposes, with humans hierarchically superior, thus it was available for exploitation by humans without any moral recourse.

The Christian perception of nature gained credence in Western European society as the authority of the Church increased, while simultaneously the support for paganism and alchemic science diminished. This position was widely accepted during the Church's zenith from the thirteenth century to the scientific revolution in the sixteenth century.

\subsection{The Scientific Revolution: from the whole to the sum of the parts}

The rapid rise in the absolute authority of science during the scientific revolution in the sixteenth century rapidly replaced the Church as the dominant authority in 
Western European society. The new science, 'Scienza Nuova', became ultimate truth: "science's power and the magic of its numbers were dazzling, overwhelming. Progressively they would exclude all possibility of competition, of alternative explanation" [3, p. 46].

Bacon (1561-1626), Descartes (1596-1650) and Newton (1643-1727) had a profound impact on changing the scientific perception of nature. The foundation of Cartesian thought, developed by Descartes, was the absolute certainty of scientific knowledge. Cartesian thought posited that the (human) mind (res cogitans, thinking thing) was superior to matter (res extensa, extended thing), and viewed living organisms (nature) as machines governed by precise mathematical laws. This became the basis of his dualistic world-view from which a natural hierarchy emerged between man (mind), who could think, and nature (matter), who according to Descartes, could not. These conclusions provided scientific justification for the anthropocentric belief, held firmly by both Bacon and Descartes, that the goal of science was to "render ourselves the masters and possessors of nature", in order to transcend any human dependence on nature $[4, \mathrm{p} .61]$.

The scientific progress made by these men was synthesised in the seventeenth century by Isaac Newton, who developed a complete mathematical formulation of the mechanistic view of nature: neutral, algorithmic, and fragmented. While he is often considered the father of modern reductionist science, much of his work focused on that which he is blamed for destroying alchemy and astrology - which he was forced to abandon due to inconclusive scientific results [3, p. 45].

As reductionist-mechanistic thinking dominated, the spiritual, magical, and intuitive elements of science were eliminated. Science became a clinical process of human self-assertion, with the aim of dominating and controlling nature. Modern science considered all living matter as without a soul, with the exception of 'rational' man. The corresponding change in the perception of the universe was from a living, organic and spiritual being, to that of a compartmentalised machine that "could be fully understood as a series of differential equations, as an algorithmic compression" [3, p. 46].

\subsection{Progress: the path we chose}

Modern science and Christianity shared the underlying belief that the concept of 'civilisation' was directly linked to the taming and improvement of brute, wild nature; as such there was a commonly held conviction that they were "completing God's work" [1, p. 147]. This viewpoint, firmly established by the eighteenth century, provided the justification for widespread domination, appropriation and destruction of the natural world. Within this social paradigm a new and pivotal discipline, economics, emerged. Unfortunately for the natural world, this social discipline shared the powerfully established anthropocentric perception of nature, and rapidly became the third pillar to the edifice of an increasingly anthropocentric Western European society. 
According to Ponting [1, p. 153], economics exercises such a profound influence upon the way the world is perceived, and is now so powerful within the Western social paradigm, that the modern view of the relationship between humans and the natural world can only be understood through the "hidden assumptions of economics and the value systems that it enshrines". Furthermore, economics "never was and never can be value free" - the fact that it emerged as a separate discipline in the nineteenth century reflects the importance in the industrialized countries of the expansion of production and consumption $[1, \mathrm{p}$. 158]. The economy became the focus of social organisation, the measure of civilization; other considerations such as quality of life and human dependence on nature were overlooked and ignored. As the power of economics escalated in the eighteenth century, the concept of progress, and by association support for economic growth, became a cornerstone of Western society.

\subsection{The current ideological basis of Western society}

Christianity, modern science, and classical economics combined within an anthropocentric framework to create a powerful edifice on which Western society stands today. Each component is mutually reinforcing; each component validates the existence of the other; and each component plays a crucial role in the sustainment of the current ideological basis of Western society. Collectively they have contributed to the dominant global forces of capitalist patriarchy which are inherently exploitative and dualistic, interpret difference as hierarchical, and consider homogeneity as a requirement for equality [5].

Modern civilisation "structurally dichotomises reality, and hierarchically opposes the two parts to each other: the one always considered superior, always thriving, and progressing at the expense of the other" [5, p. 5]. These inherent inequalities in world structure enable humans to dominate nature, and justify the ongoing appropriation and pollution of natural resources. Reductionistmechanistic science and technology simultaneously create "the measure of value and the instruments for the annihilation of that which it considers non-value" $[5$, p. 25].

\section{The institutionalisation of anthropocentrism}

Anthropocentrism is the practice, conscious or otherwise, of regarding the existence and concerns of human beings as the central purpose of universal existence. The objective of this ideology was to enable human beings to impose a sense of order and meaning on the world, and provide humanity with an individual and collective identity.

Anthropocentrism has been posited as the primary (though frequently unstated) reason why humanity consistently attempts to dominate nature. Through a dualistic framework, it views urban centres and the 'civilization' in them as the real world, rather than nature. 'Nature' is safely contained to designated reserves - enclosed, isolated pockets in vast areas dominated by 
human activities. Within this context, anthropocentrism has been identified by some as a root cause of, among other issues, the ecological crisis, human overpopulation, and the extinctions of many non-human species.

\subsection{Anthropocentric perception of nature}

Anthropocentrism is an obstacle to sustainable development as it promotes dualisms, hierarchies, and the belief that humans are separate from nature. This mental and physical detachment enables humans to feel no connection to nature, and has contributed to the notion that the biosphere is here for our consumption. Further, the notion that non-humans have value only in so far as humans accord value to them is inherent in the belief that humans are the source of all value, and is the fundamental basis for anthropocentric thought. As such, it is generally held that "human beings are the only proper objects of human moral concern" [6, p. $109]$, and any duties towards the non-human world are in fact indirect duties to humans.

Western society now perceives natural systems through a reductionistmechanistic framework, and as such they are no more than a collection of parts to be examined and understood in order to be engineered, technologically conquered, and appropriated. The attitude to natural systems promoted by reductionist science was adversarial - the Western concept of human freedom and happiness depended on an ongoing emancipation from nature, and dominance over natural processes, thereby overcoming this dependence by the power of reason and rationality, and the subordination of nature to human desire.

This is the basis for the current capitalist patriarchal world system which has been facilitated by, is built upon, and maintains itself through the colonisations of, among others, nature, which it is progressively destroying [5]. It facilitates an economic regime where the processes of modernisation and development, and the concept of progress, necessarily require the destruction and appropriation of the natural environment.

\subsection{Anthropocentric approach to environmental policy}

An anthropocentric approach to environmental policy is an obstacle to sustainable development primarily because it advocates a managerial approach to environmental problems, confident that they can be solved without significant changes in the current patterns of production and consumption. This is evident in the anthropocentric approach to environmental decision-making regarding environmental policy, which tends to have the following characteristics. The first is that it is often reactive, tactical, piecemeal and end-of-pipe; the second is the policy of 'pollution displacement'; and the third is that it generally adheres to the principle of 'no proof, no response' [7, p. 7].

Further, a significant proportion of the anthropocentric approach to environmental policy is embedded in the anthropocentric and technocentric viewpoint that there are no limits to growth. This position claims that technology will provide a solution to any problems faced by an increasing population. 
Conversely, others argue for the finite carrying capacity of the earth, citing food shortages due to limited agricultural land as the primary determinant. Within this framework, arguments for population control and reduction are generally made with reference to developing nations where there is evidence of widespread poverty. However, Ehrlich [8, p. 916] points out "While overpopulation in poor nations tends to keep them poverty-stricken, overpopulation in rich nations tends to undermine the life-support capacity of the entire planet."

\subsection{The concept of sustainable development}

Within this context, a fundamental obstacle to achieving sustainable development is the definition itself, and its ideological basis. While the first wave of environmentalism was "characterised as being anti-development" [9, $\mathrm{p}$. xii], the second wave of environmentalism in the late 1980s, promoting sustainable development, was decidedly pro-development. This may be due in part to the anthropocentric economic and political environment in which the notion of sustainable development was conceived.

In 1987 the World Commission on Environment and Development produced a report, Our Common Future (Brundtland Report), whose primary thrust was sustainable development, which was defined as "Development that meets the needs of the present without compromising the ability of future generations to meet their own needs" [9, $p$ xiii].

The Brundtland Report focused exclusively on the needs and interests of humans, with the goal of achieving global equity for future generations by redistributing resources from developed nations to developing nations. The Brundtland Report believed all human beings should be able to meet their basic needs; and that social equity, economic growth and environmental maintenance are simultaneously possible. Further, it stated that each nation is capable of achieving its full economic potential whilst at the same time enhancing its resource base. However, it conceded that achieving this equity and sustainable growth would require technological and social change [10].

The 1987 Brundtland Report was quickly accepted in political and commercial spheres, and the idea of sustainable development became politically orthodox $[11$, p. 1] due to the understanding that sustainable development and economic growth were not mutually exclusive. This definition of sustainable development "offers the promise that economic activities can be harmonised with environmental protection, that technologies can be found and implemented that will ensure economic growth does not harm the environment, and that pressing environmental problems can be solved without social and political disruption" $[9, \mathrm{p}$ xi] .

However, an inherent flaw in the definition of sustainable development is that it "largely displaces the discourse of limits and survivalism that were features of writing about the environment in the early 1970s, although these limits were not disproved by sustainable development, instead they were assumed away" [7, p. 7]. 


\section{Anthropocentrism and sustainable development: oxymoron or symbiosis?}

\subsection{Achieving sustainable development within the current Western paradigm}

Christianity, modern science, and classical economics combined within an anthropocentric framework to create the current Western social paradigm. Within this context, acting in self-interest was posited by classical economics as the most efficient form of organizing the economy, and due to the immense influence of economics, society. Acting in self-interest has developed into excessive consumerism, greed and what Fricker [12, p. 430] describes as "noxious wants" in the twentieth century. This position was further justified and legitimized by anthropocentrism, expressed in various forms through Christianity, modern science, and a dominator model of social organisation.

Thus it is unlikely that the current definition of sustainable development, within the context of the current ideological basis of Western society, can be interpreted and implemented as anything other than anthropocentric, and therefore inherently human-centered, at the expense of the natural environment.

\subsection{Re-defining sustainable development within the current Western paradigm}

The current definition of sustainable development is inherently qualitative; it resembles a performance based guideline rather than a prescriptive guideline. Even if it is viewed as a set of performance guidelines, the performance outcomes are very broad (meets the needs of the present generation) and to some extent, intangible (without compromising the ability of future generations to meet their needs). This presents two problems within a quantitative system: firstly, defining, and reaching consensus worldwide, regarding what are acceptable 'needs'; and secondly, measuring an acceptable level of these 'needs'.

Western society operates within a reductionist-mechanistic social and policy-making framework; thus we have been unable to reconcile a qualitative definition (even as performance guidelines) of sustainable development with a reductionist-mechanistic outcome - there is no capacity for translating one into the other. In the absence of a clearly defined goal or outcome, and empirical evidence to illuminate the path that should be taken, Western society appears to be at a loss to know how to effectively implement the definition.

Within the current anthropocentric approach to environmental policy, if a phenomenon cannot be proved, it is considered invalid. Just like Newton before us, there is growing evidence that we are being forced to abandon sustainable development as a concept, that we know intuitively to be true, but which we cannot prove. We are choosing to only see a fragment of the picture, the part that fits into a reductionist-mechanistic framework, at the expense of whole living systems, and the physical manifestations of this inaction are gradually destroying us.

Thus, in order to re-define sustainable development within an anthropocentric framework, it would have to be translated into a quantitative 
definition that is not inherently anthropocentric, and that places greater emphasis on inter-species equity, rather than simply inter- and intra- generational equity among humans. It would concede that ongoing economic growth and preserving the natural environment in an uncompromised (or at least functioning) state are not simultaneously possible or symbiotic - that in fact one excludes the possibility of the other.

Rather, achieving inter-species equity will require humans (particularly in developing countries) to take a lesser share of the natural environment. Further, a quantitative definition would clearly outline obstacles in the current patterns of social organization, production and consumption in Western society, and identify a methodology embedded in reductionist-mechanistic science for achieving a sustainable outcome.

As the precautionary principle is routinely ignored in Western society, the burden of proof remains with the natural environment; thus the empirical data required to prove to both governments and society that these measures are required is most likely insurmountable. Furthermore, the data indicating the impact we are having on the biosphere is difficult to both gather and collate into coherent empirical evidence (for example, tracking climate change). Thus, this course of action is an undertaking that, in the absence of support from either government or society, would be difficult to mobilize and follow through to completion, and as such is unlikely to happen.

\subsection{Re-conceptualising anthropocentrism within the current Western paradigm}

Reductionist-mechanistic science is fundamental to sustaining Western society in its current form. As Mies and Shiva [5, p. 24] point out, "Far from being an epistemological accident, reductionism is a response to the need for a particular form of economic and political organization. The reductionist world-view, the industrial revolution and the capitalist economy are the philosophical, technological and economic components of the same process." They are so tightly integrated, that to extract one from the others is virtually impossible.

Thus, the action necessary to reconceptualise anthropocentrism within the current paradigm, and enable the survival of the earth, will demand a "radical rethinking of many of the most sacrosanct assumptions of the dominant culture of the Western world, and it will involve sweeping changes in cultural arrangements" [13, p. 157]. Diamond [15] further suggests that human survival will hinge on a future of significantly lower living standards, chronically higher risks, and the undermining of what we now consider to be some of our key values.

While many people may find it difficult to believe that alternative social models are possible, if we "free ourselves from the prevailing models of reality, it is evident that there is another logical alternative; that there can be societies in which difference is not necessarily equated with inferiority or superiority" $[15$, p. xvii]. Within this partnership model of society, the social relations are primarily based on the principle of linking rather than ranking; they celebrate 
life, birth and the regenerative processes of nature rather than revering death and violence.

In order to create a partnership model of organisation, Western society would have to undergo a process of cultural reform, which Boyden [13] defines as a cultural response aimed at overcoming undesirable consequences of cultural maladaptation (an activity that is the product of a cultural fallacy, and that causes unnecessary distress to humans, or unnecessary damage to other living systems in the biosphere). Within this context, it is important to note the difference between corrective reform, which is a cultural response to a culturally induced environmental threat that aims to correct the underlying cause of the threat; and antidotal reform, which is a cultural response to a culturally induced environmental threat that is directed at the signs or symptoms of the threat, but not at the underlying cause [13].

The current definition of sustainable development, and the policies derived from this, generally fall within the category of antidotal reform - they rarely solve the underlying issue, and merely deal with the physical manifestations of current patterns of production and consumption that meet the least resistance when modified. A clear example is recycling rubbish - rather than educating society to consume less, the current rate of consumption is justified by recycling the extraneous packaging.

The process of creating a partnership society would facilitate the reconceptualisation of other fundamental disciplines. For example, the current Western economic system could be transformed into what E.F.Schumacher describes as "Buddhist economics", which includes spiritual values [16, p. 207]. Within the framework of a partnership society and re-conceived social disciplines, the re-conceptualisation and re-definition of sustainable development would include sustainability for all living systems on earth, not simply humans as one element of a larger ecosystem, at the expense of the ecosystem.

\section{Conclusion}

The anthropocentric belief that humans are the only source of value in the world predisposes all economic, social and political motivations to improving the situation of humans at the expense of the non-human world, with questionable results for both man and nature. Further, anthropocentric approaches to environmental thought reinforce the notion that humans are separate from nature, and will somehow be immune to the negative effects of our current patterns of production and consumption.

While these issues impact on the achievement of sustainable development, the definition itself has an anthropocentric basis and therefore places more importance on economic and social sustainability rather than environmental. As a result, "Everything that is normally described as an 'environmental' problem could be more accurately called an environmental symptom of a human problem" [17].

Thus, re-defining sustainable development from a qualitative to a quantitative guideline within the current anthropocentric paradigm is not only an 
enormous task, it is unlikely to yield truly sustainable results due to the inherently human-centered ethos of the current Western paradigm. Consequently, anthropocentrism and sustainable development appear to be mutually exclusive, and as such are an oxymoron.

A re-conceptualisation of Western society as a partnership society, in which dualisms do not facilitate the belief in a natural hierarchy between humans and nature, would produce a more substantive outcome. A re-conceptualised Western paradigm would provide the framework for re-defining sustainable development such that it enables the indefinite continuation of the biosphere, and thus humans, in an uncompromised state.

\section{References}

[1] Ponting, C., Ways of thought (Chapter 8). A Green History of the World, Penguin Books: New York, pp. 141-160, 1991.

[2] King James Bible.

[3] Appleyard, B., Understanding the Present: Science and the Soul of Modern Man, Pan Books Ltd: London, 1992.

[4] Capra, F., The Turning Point: Science, Society, and the Rising Culture, Bantom Books: New York, 1982.

[5] Mies, M., \& Shiva, V., Ecofeminism, Spinifex Press: Melbourne, 1993.

[6] Warren, M., The rights of the non human world. Environmental Philosophy, ed Elliot \& Gare, pp. 109-134, 1983.

[7] Coffey, B., Environmental Politics, Class Notes, RMIT University: Melbourne, 2002.

[8] Ehrlich, P., Population, Plenty, and Poverty. Time, December, p. 914, 1988.

[9] Beder, S., The Nature of Sustainable Development, Scribe: Newham, pp. 11-15, 1993.

[10] Dresner, S., The Principles of Sustainability, Earthscan Publications Ltd: London, 2002.

[11] Kirkby, J., Introduction. The Earthscan Reader in Sustainable Development, ed. J. Kirkby et al, Earthscan Publications: London, 1995.

[12] Fricker, A., The ethics of enough. Futures, 34, pp. 427-433, 2002.

[13] Mies, M. \& Shiva, V., Ecofeminism, Spinifex Press: Melbourne, 1993.

[14] Boyden, S., The Biology of Civilisation: Understanding Human Culture as a Force in Nature, UNSW Press: Sydney, 2004.

[15] Diamond, J., Collapse: How Societies Choose to Fail or Survive, Penguin Group: Melbourne, 2005.

[16] Eisler, R., The Chalice and the Blade, Unwin Hyman Ltd: Great Britain, 1990.

[17] Kumar, S., E.F. Schumacher (Chapter 34). Fifty Key Thinkers on the Environment, ed. J.A. Palmer, Routeledge: London, pp. 205-210, 2001.

[18] Mukhtar, S., Embodied Energy of Building Materials?, http://www.strategicdata.co.nz/mukhtar/sam2.htm. 